\title{
Efficacy of Body Weight Reduction on the SGLT2 Inhibitor in People with Type 2 Diabetes Mellitus
}

\author{
Hyun A Cho, Young Lee Jung, Yong Hoon Lee, Yu Chang Lee, Jung Eun Lee, Sol Jae Lee, Su Jin Jeong, Chong Hwa Kim* \\ Division of Endocrinology and Metabolism, Department of Internal Medicine, Sejong General Hospital, Bucheon, Korea
}

Background: Dapagliflozin, a sodium-glucose cotransporter-2 inhibitor, reduces hyperglycemia and body weight by inhibiting renal glucose reabsorption. However, only a few studies have demonstrated efficacy of dapagliflozin for type 2 diabetic patients in Korea. We evaluated the efficacy and safety of dapagliflozin for Korean type 2 diabetes patients.

Methods: This is a retrospective study that included data from 61 patients who received 12 months of dapagliflozin therapy and who visited a single medical center between January 2015 and July 2016. Patients were separated into three groups: dual combination of dapagliflozin and metformin, triple combination of dapagliflozin and metformin with sulfonylurea, or dipeptidyl peptidase IV inhibitors, and quadriple combination of dapagliflozin, metformin, and sulfonylurea with dipeptidyl peptidase IV inhibitors. Patients who achieved $\geq 5 \%$ body weight reduction were classified as responders, and those who achieved $<5 \%$ body weight reduction were classified as non-responders.

Results: After 12 months, the mean change from baseline body weight was $-3.4 \pm 2.6 \mathrm{~kg}(P<0.001)$ for all patients, $-3.4 \pm 3.1 \mathrm{~kg}(P<0.001)$ for group $1,-2.7 \pm 2.0 \mathrm{~kg}(P=0.008)$ for group 2 , and $-4.0 \pm 2.3 \mathrm{~kg}(P<0.001)$ for group 3. Fasting $C$-peptide level was higher in the responder group than in the non-responder group (3.25 \pm $1.07 \mathrm{ng} / \mathrm{mL}$ vs. $2.62 \pm 1.02 \mathrm{ng} / \mathrm{mL}, P=0.023)$. In total, reductions in HbA1c, PP2, and FPG levels were $-0.61 \pm$ $0.82 \%(P=0.000),-35.4 \pm 62 \mathrm{mg} / \mathrm{dL}(P=0.000)$, and $-21.3 \pm 56.2 \mathrm{mg} / \mathrm{dL}(P=0.012)$, respectively. They had mild adverse events included orthostatic dizziness and urinary tract infection.

Conclusion: SGLT2 inhibitor improved glycemic control and reduced body weight in a safe manner for patients with type 2 diabetes mellitus.

Key words: SGLT2 inhibitor, Dapagliflozin, Body weight reduction

Received September 7, 2016

Reviewed October 3, 2016

Accepted November 4, 2016

*Corresponding author

Chong Hwa Kim

(i)

http://orcid.org/0000-0002-4563-7772

Division of Endocrinology and Metabolism, Department of Internal Medicine, Sejong General Hospital, 28 Hohyeon-ro 489beon-gil, Sosa-gu, Bucheon 14754, Korea

Tel: +82-32-340-1116

Fax: +82-32-340-1834

E-mail: drangelkr@hanmail.net

\section{INTRODUCTION}

Recent studies have shown that intensive glucose control reduced the incidence of diabetes-related complications. ${ }^{1,2}$ However, tight glycemic control is also associated with hypoglycemic events and weight gain. Furthermore, obesity prevalence has increased rapidly due several factors, including genetic predisposition, environmental exposure, and aging processes. Also, obesity has been associated with diabetes incidence and diabetes complications.
Dapagliflozin, a highly selective sodium-glucose cotransporter-2 (SGLT-2) inhibitor, reduces hyperglycemia by inhibiting renal glucose reabsorption and increasing urinary glucose excretion. Dapagliflozin has also been associated with caloric consumption, leading to weight loss and reduced blood pressure.-8

Several randomized-control clinical trials have demonstrated the efficacy of dapagliflozin compared to other oral antidiabetic agents, such as metformin, sulfonylurea, dipeptidyl peptidase IV (DPP-4) inhibitors, and thiazolidinediones.-8 However, only a few of these 
studies evaluated dapagliflozin efficacy in type 2 diabetic patients in Korea. Here, we address not only the efficacy of dapagliflozin for Korean type 2 diabetes patients, but also the parameters that predict body weight reduction among dapagliflozin-administered patients in clinical practice in Korea.

\section{METHODS}

This was a retrospective, cross-sectional study analyzing data from 61 patients who received a minimum of 12 months of dapagliflozin therapy (10 mg, once daily) at Sejong General Hospital between January 2015 and July 2016. Patients were selected according to the following inclusion criteria: age between 18-75 years, type 2 diabetes mellitus (T2DM), and use of dapagliflozin for longer than 12 months. Exclusion criteria were a therapy regimen that included insulin or a glucagon like peptide-1 (GLP-1) agonist; type $1 \mathrm{DM}$, gestational diabetes mellitus (GDM), or maturity onset diabetes of the young (MODY); active cancer; or lost to follow-up. Enrolled patients were classified into one of three treatment regimens: group 1) a dual combination of dapagliflozin and metformin; group 2) a triple combination of dapagliflozin and metformin with sulfonylurea or dipeptidyl peptidase IV (DPP-4) inhibitors; group 3) a quadriple combination of dapagliflozin, metformin, and sulfonylurea with DPP-4 inhibitors (Fig. 1). This study was approved by the Institutional Review Board (IRB) of Sejong General Hospital.

\section{Statistical analysis}

All statistical computations were performed using SPSS version 23.0 (IBM Corp., Armonk, NY, USA). Data were reported as mean \pm standard deviation. For analysis of the entire patient sample, we performed Kruskal-Wallis tests. Wilcoxon signed-rank tests were used to compare values before and after dapagliflozin use. Statistical comparisons between the groups to identify responders and non-responders were performed using the Mann-Whitney test. Data with a $P<0.05$ were considered significant.

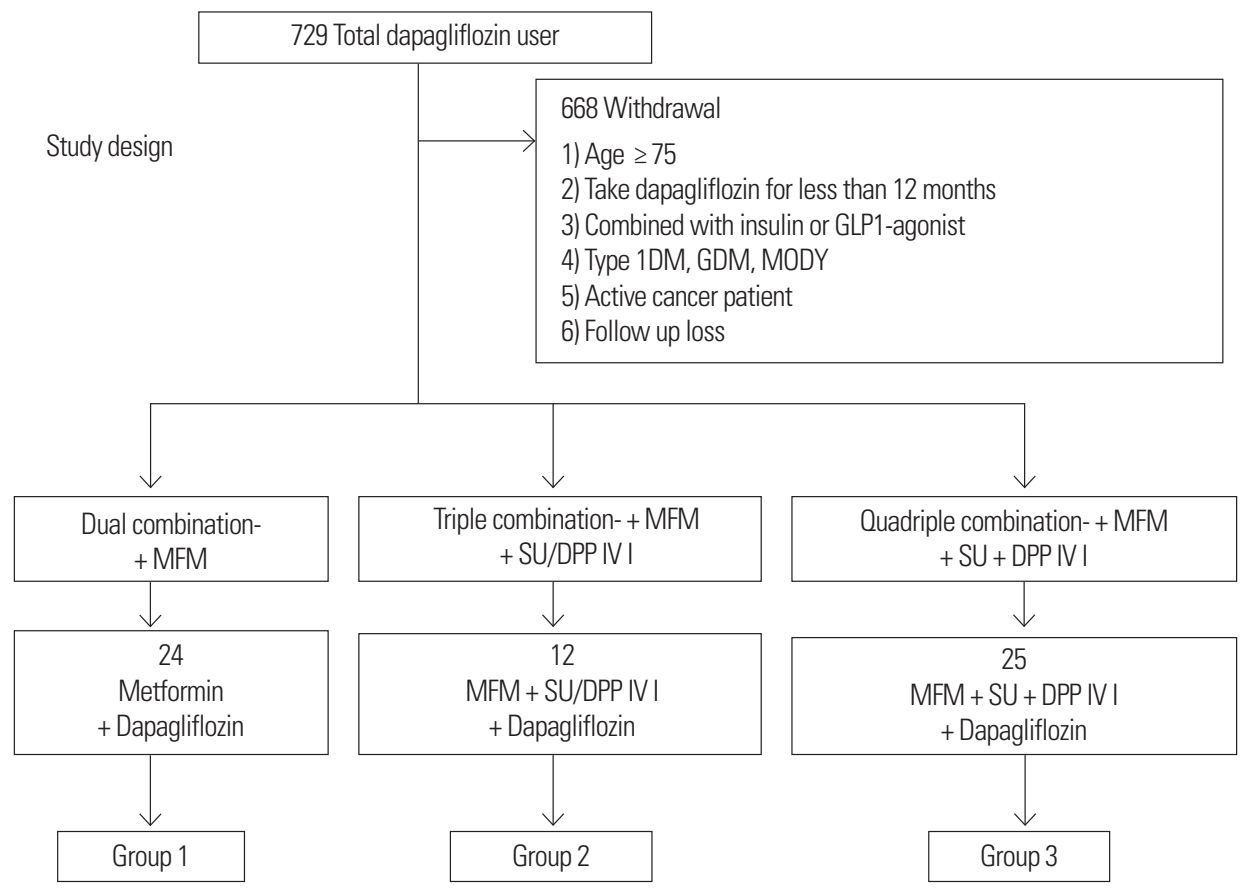

Figure 1. Study flow. We analyzed data from 61 patients who underwent a minimum of 12 months of dapagliflozin therapy (10 mg once-daily) and who visited Sejong General Hospital between January 2015 and July 2016. Patients were selected according to the following inclusion criteria: age between 18-75 years and type 2 DM. Patients were excluded if they took dapagliflozin for less than 12 months; their therapy was combined with an insulin or GLP-1 agonist; they had type 1 DM, GDM, or MODY; they were an active cancer patient; or were lost to follow-up. Patients were assigned to one of three ongoing dapagliflozin+ treatment regimens: group 1) metformin; group 2) metformin with sulfonylurea or dipeptidyl-peptidase IV (DPP-4) inhibitors; group 3) metformin and sulfonylurea with dipeptidyl peptidase IV (DPP-4) inhibitors (Group 3). GLP-1, glucagon like peptide-1; GDM, gestational diabetes mellitus; MODY, maturity onset diabetes of the young; MFM, metformin; SU, sulfonylureas; DPP-IV I, dipeptidy peptidase IV inhibitors. 


\section{RESULTS}

\section{Baseline characteristics of the subjects}

We reviewed 729 diabetic subjects who visited the department of endocrinology and metabolism at Sejong General Hospital in Bucheon, Korea, between January 2015 and July 2016. Among 61 enrolled type 2 diabetic subjects, 32 (52.5\%) were men and 29 (47.5\%) were women. In this study, the treatment group, who received $10 \mathrm{mg}$ of dapagliflozin once daily, experienced significant decreases in all glucose parameters for type 2 diabetes mellitus. Table 1 summarizes the baseline characteristics of the subjects. Mean age and DM duration were $58.5 \pm 9.6$ years and $11.4 \pm 5.6$ years, respectively, while mean body weight and baseline body mass index (BMI) were $72.6 \pm 12.1 \mathrm{~kg}$ and $27.3 \pm 3.6 \mathrm{~kg} / \mathrm{m}^{2}$, respectively. More than half of the patients in our study were obese $(60 \%$, $\mathrm{n}=37$ ). Mean HbA1c, 2-hour postprandial plasma glucose (PP2) level, and fasting plasma glucose (FPG) level were $7.6 \pm 1.0 \%$,
$194.2 \pm 69.8 \mathrm{mg} / \mathrm{dL}$, and $163.8 \pm 60.3 \mathrm{mg} / \mathrm{dL}$, respectively. Mean creatinine and eGFR levels were $0.86 \pm 0.22 \mathrm{mg} / \mathrm{dL}$ and $87.2 \pm 18.6$ $\mathrm{ml} / \mathrm{min}$, respectively. There were no detrimental effect on renal function over period of dapagliflozin add-ons.

\section{Metabolic effects of dapagliflozin included glycemic and lipid control}

All treatment groups experienced improvements in $\mathrm{HbAlc}$, PP2, and FPG. For the total subject sample, reductions in $\mathrm{HbAlc}$, PP2, and FPG levels were $-0.61 \pm 0.82 \%(P<0.001),-35.4 \pm 62 \mathrm{mg} / \mathrm{dL}$ $(P<0.001)$, and $-21.3 \pm 56.2 \mathrm{mg} / \mathrm{dL}(P=0.012)$, respectively. For group 1, the reductions in $\mathrm{HbA1c}$, PP2, and FPG levels were $0.39 \pm 0.80 \%(P=0.093),-19.2 \pm 41.0 \mathrm{mg} / \mathrm{dL}(P=0.152)$, and $-16.0 \pm 33.3 \mathrm{mg} / \mathrm{dL}(P=0.088)$, respectively. For group 2 , the reductions in $\mathrm{HbA1c}$, PP2, and FPG levels were $-0.93 \pm 1.0 \%$ $(P=0.018),-63.1 \pm 90.6 \mathrm{mg} / \mathrm{dL}(P=0.034)$, and $-22.4 \pm 99.0 \mathrm{mg} /$ $\mathrm{dL}(P=0.790)$, respectively. For group 3 , the reductions in $\mathrm{HbA1c}$,

Table 1. Baseline characteristics of the subjects

\begin{tabular}{|c|c|c|c|c|c|}
\hline Variable & Total $(n=61)$ & G1 $(n=24)$ & $G 2(n=12)$ & $\mathrm{G} 3(\mathrm{n}=25)$ & $P$ \\
\hline Age (yr) & $58.5 \pm 9.6$ & $59.9 \pm 10.4$ & $57.1 \pm 12.0$ & $57.8 \pm 7.5$ & 0.652 \\
\hline Male sex (\%) & $32(52.5)$ & $12(50)$ & $7(58)$ & 12 (48) & 0.893 \\
\hline Duration of DM (yr) & $11.4 \pm 5.6$ & $8.2 \pm 4.0$ & $13.3 \pm 5.1$ & $13.6 \pm 5.8$ & $0.001^{*}$ \\
\hline Weight (kg) & $72.6 \pm 12.1$ & $72.6 \pm 12.1$ & $73.5 \pm 13.4$ & $72.0 \pm 11.9$ & 0.938 \\
\hline Height (m) & $1.63 \pm 0.08$ & $1.61 \pm 0.07$ & $1.65 \pm 0.08$ & $1.63 \pm 0.09$ & 0.513 \\
\hline $\mathrm{BMI}\left(\mathrm{kg} / \mathrm{m}^{2}\right)$ & $27.3 \pm 3.6$ & $27.8 \pm 3.7$ & $26.9 \pm 3.6$ & $27.0 \pm 3.7$ & 0.690 \\
\hline $\mathrm{SBP}(\mathrm{mmHg})$ & $132.1 \pm 11.6$ & $132.5 \pm 10.7$ & $132.3 \pm 19.3$ & $131.6 \pm 7.6$ & 0.968 \\
\hline $\mathrm{DBP}(\mathrm{mmHg})$ & $80.2 \pm 7.7$ & $80.7 \pm 7 . .0$ & $81.8 \pm 9.3$ & $79.0 \pm 7.8$ & 0.562 \\
\hline $\mathrm{HbA1c}(\%)$ & $7.6 \pm 1.0$ & $6.87 \pm 0.80$ & $7.75 \pm 1.04$ & $8.17 \pm 0.73$ & $<0.001$ \\
\hline PP2 (mg/dL) & $194.2 \pm 69.8$ & $162.5 \pm 43.1$ & $223.7 \pm 111.2$ & $210.4 \pm 54.8$ & $0.012^{*}$ \\
\hline Fasting plasma glucose (mg/dL) & $163.8 \pm 60.3$ & $149.3 \pm 48.3$ & $168.3 \pm 85.2$ & $173.5 \pm 54.8$ & 0.265 \\
\hline Total cholesterol (mg/dL) & $144.4 \pm 31.3$ & $140.4 \pm 33.6$ & $151.3 \pm 36.8$ & $144.9 \pm 36.8$ & 0.624 \\
\hline Triglycerides (mg/dL) & $138.3 \pm 69.5$ & $136.8 \pm 63.4$ & $124.9 \pm 77.6$ & $146.2 \pm 72.9$ & 0.686 \\
\hline $\mathrm{HDL}-\mathrm{C}(\mathrm{mg} / \mathrm{dL})$ & $48.9 \pm 11.2$ & $49.3 \pm 12.9$ & $48.6 \pm 8.6$ & $48.7 \pm 10.8$ & 0.978 \\
\hline LCL-C (mg/dL) & $77.2 \pm 26.5$ & $74.1 \pm 30.0$ & $85.8 \pm 28.7$ & $76.0 \pm 21.7$ & 0.452 \\
\hline BUN (mg/dL) & $16.3 \pm 5.6$ & $16.0 \pm 4.6$ & $16.6 \pm 4.8$ & $16.5 \pm 6.8$ & 0.949 \\
\hline $\mathrm{Cr}(\mathrm{mg} / \mathrm{dL})$ & $0.86 \pm 0.22$ & $0.85 \pm 0.19$ & $0.82 \pm 0.24$ & $0.89 \pm 0.23$ & 0.604 \\
\hline $\mathrm{eGFR}(\mathrm{mL} / \mathrm{min})$ & $87.2 \pm 18.6$ & $86.9 \pm 16.8$ & $91.8 \pm 21.5$ & $85.4 \pm 19.1$ & 0.622 \\
\hline BUN (mg/dL, 12 mo later) & $17.1 \pm 4.7$ & $17.3 \pm 5.1$ & $18.3 \pm 4.3$ & $16.4 \pm 4.4$ & 0.424 \\
\hline $\mathrm{Cr}$ (mg/dL, 12 mo later) & $0.82 \pm 0.21$ & $0.81 \pm 0.18$ & $0.81 \pm 0.24$ & $0.84 \pm 0.22$ & 0.763 \\
\hline eGFR (mL/min, 12 mo later) & $89.5 \pm 16.8$ & $89.1 \pm 14.0$ & $93.3 \pm 20.1$ & $88.0 \pm 18.0$ & 0.747 \\
\hline
\end{tabular}

Values are presented as mean \pm standard deviation or number $(\%)$.

${ }^{*} P<0.05$

G, group; yr, year; DM, diabetes mellitus; BMI, body mass index; SBP, systolic blood pressure; DBP, diastolic blood pressure; HbA1c, glycated hemoglobin; PP2, post prandial plasma glucose 2 hours; HDL-C, high-density lipoprotein cholesterol; LDL-C, low-density lipoprotein cholesterol; BUN, blood urea nitrogen; Cr, creatinine; eGFR, estimated glomerular filtration rate. 
PP2, and FPG levels were $-0.65 \pm 0.71 \%(P=0.002),-37.9 \pm 61.4$ $\mathrm{mg} / \mathrm{dL}(P=0.001)$, and $-24.8 \pm 42.4(P=0.039)$, respectively (Table 2). There was an incremental increase of $2.4 \pm 7.7 \mathrm{mg} / \mathrm{dL}$ in high density lipoprotein-cholesterol (HDL-C) level for the total patient sample $(P=0.068)$; however, this increase was not statistically significant (Table 3 ).

\section{Effects of dapagliflozin on body weight and blood pressure}

Table 2 shows mean changes between baseline and 12 months after therapy initiation for body weight (BWT), systolic blood pressure (SBP), and diastolic blood pressure (DBP). After 12 months, the mean change in BWT was $-3.4 \pm 2.6 \mathrm{~kg}(P<0.001)$ for the total sample, $-3.4 \pm 3.1 \mathrm{~kg}(P<0.001)$ for group $1,-2.7 \pm 2.0 \mathrm{~kg}$ $(P=0.008)$ for group 2 , and $-4.0 \pm 2.3 \mathrm{~kg}(P<0.001)$ for group 3 . The mean change in SBP was $-6.0 \pm 14 \mathrm{mmHg}(P=0.001)$ for the total sample, $-6.0 \pm 16 \mathrm{mmHg}(P=0.146)$ for group $1,-6.6 \pm 17.9$
$\operatorname{mmHg}(P=0.165)$ for group 2 , and $-5.1 \pm 10.0 \mathrm{mmHg}(P=0.013)$ for group 3. The mean change in DBP was $-3.4 \pm 7.7 \mathrm{mmHg}$ $(P=0.002)$ for the total sample, $-3.0 \pm 8.4 \mathrm{mmHg}(P=0.109)$ for group $1,-5.8 \pm 9.3 \mathrm{mmHg}(P=0.064)$ for group 2 , and $-2.7 \pm 6.3$ $\mathrm{mmHg}(P=0.092)$ for group 3 .

\section{Predictive clinical parameters of body weight reduction in the dapagliflozin responder group}

Patients who achieved a BWT reduction $\geq 5 \%$ were classified into the responder group, and those with $<5 \%$ body weight reduction were classified into the non-responder group. We analyzed for influencing factors in the responder group and found that baseline fasting C-peptide level was higher in the responder group than in the non-responder group $(3.25 \pm 1.07 \mathrm{ng} / \mathrm{mL}$ vs. $2.62 \pm 1.02 \mathrm{ng} /$ $\mathrm{mL}, P=0.023$; Table 4). Baseline fasting C-peptide level was a significant clinical parameter in the dapagliflozin response group ( $\mathrm{Ta}$ ble 4). In the responder and non-responder groups, serum fasting

Table 2. Metabolic effects on body weight, blood pressure, and glycemic control after one year of dapagliflozin treatment

\begin{tabular}{|c|c|c|c|c|c|c|}
\hline Group & $\Delta \mathrm{BWT}(\mathrm{kg})$ & $\Delta \mathrm{SBP}(\mathrm{mmHg})$ & $\triangle \mathrm{DBP}(\mathrm{mmHg})$ & $\Delta \mathrm{HbA} 1 \mathrm{c}(\%)$ & $\Delta \mathrm{PP} 2(\mathrm{mg} / \mathrm{dL})$ & $\Delta \mathrm{FPG}(\mathrm{mg} / \mathrm{dL})$ \\
\hline Total & $-3.4 \pm 2.6$ & $-6.0 \pm 14$ & $-3.4 \pm 7.7$ & $-0.61 \pm 0.82$ & $-35.4 \pm 62$ & $-21.3 \pm 56.2$ \\
\hline Group $1+2+3$ & $P<0.001^{*}$ & $P=0.001^{*}$ & $P=0.002^{*}$ & $P<0.001^{*}$ & $P<0.001^{*}$ & $P=0.012^{*}$ \\
\hline Group 1 & $-3.4 \pm 3.1$ & $-6.0 \pm 16$ & $-3.0 \pm 8.4$ & $-0.39 \pm 0.80$ & $-19.2 \pm 41.0$ & $-16.0 \pm 33.3$ \\
\hline (Dual combination) & $P<0.001^{*}$ & $P=0.146$ & $P=0.109$ & $P=0.093$ & $P=0.152$ & $P=0.088$ \\
\hline Group 2 & $-2.7 \pm 2.0$ & $-6.6 \pm 17.9$ & $-5.8 \pm 9.3$ & $-0.93 \pm 1.0$ & $-63.1 \pm 90.6$ & $-22.4 \pm 99.0$ \\
\hline (Triple combination) & $P=0.008^{*}$ & $P=0.165$ & $P=0.064$ & $P=0.018^{*}$ & $P=0.034^{*}$ & $P=0.790$ \\
\hline Group 3 & $-4.0 \pm 2.3$ & $-5.1 \pm 10.0$ & $-2.7 \pm 6.3$ & $-0.65 \pm 0.71$ & $-37.9 \pm 61.4$ & $-24.8 \pm 42.4$ \\
\hline (Quadriple combination) & $P<0.001^{*}$ & $P=0.013^{*}$ & $P=0.092$ & $P=0.002^{*}$ & $P=0.001^{*}$ & $P=0.039^{*}$ \\
\hline
\end{tabular}

Values are presented as mean \pm standard deviation.

${ }^{*} P<0.05$.

$\triangle$, difference between values before and after one year of treatment; BWT, body weight; SBP, systolic blood pressure; DBP, diastolic blood pressure; HbA1c, glycated hemoglobin; PP2, post prandial plasma glucose 2 hours; FPG, fasting plasma glucose.

Table 3. Metabolic effects on lipid profiles after one year of dapagliflozin treatment

\begin{tabular}{|c|c|c|c|c|c|}
\hline Group & $\Delta$ Total cholesterol (mg/dL) & $\Delta \mathrm{TG}(\mathrm{mg} / \mathrm{dL})$ & $\Delta \mathrm{HDL}-\mathrm{C}(\mathrm{mg} / \mathrm{dL})$ & $\Delta \mathrm{LCL}-\mathrm{C}(\mathrm{mg} / \mathrm{dL})$ & $\Delta$ Non-HDL-C (mg/dL) \\
\hline Total & $0.71 \pm 27.2$ & $-4.4 \pm 56.5$ & $2.4 \pm 7.7$ & $-2.4 \pm 25.2$ & $-1.7 \pm 27.0$ \\
\hline Group $1+2+3$ & $P=0.093$ & $P=0.200$ & $P=0.068$ & $P=0.366$ & $P=0.289$ \\
\hline Group 1 & $-1.3 \pm 32.1$ & $-0.25 \pm 57.9$ & $5.0 \pm 15.4$ & $-4.4 \pm 27.8$ & $-10.5 \pm 56.7$ \\
\hline (Dual combination) & $P=0.405$ & $P=0.541$ & $P=0.307$ & $P=0.541$ & $P=0.286$ \\
\hline Group 2 & $-3.58 \pm 24.9$ & $-7.8 \pm 65.8$ & $3.5 \pm 9.3$ & $-10.4 \pm 17.6$ & $-7.1 \pm 19.3$ \\
\hline (Triple combination) & $P=0.774$ & $P=0.146$ & $P=0.388$ & $P=0.388$ & $P=0.774$ \\
\hline Group 3 & $-0.36 \pm 25.3$ & $-6.8 \pm 52.5$ & $1.64 \pm 6.5$ & $1.24 \pm 24.0$ & $-2.0 \pm 26.2$ \\
\hline (Quadriple combination) & $P=0.424$ & $P=0.424$ & $P=0.405$ & $P=0.307$ & $P=0.678$ \\
\hline
\end{tabular}

Values are presented as mean \pm standard deviation.

$\Delta$, difference in values before and after one year of treatment; TG, triglycerides; HDL-C, high-density lipoprotein cholesterol; LDL-C, low-density lipoprotein cholesterol. 
insulin levels were $13.6 \pm 5.9 \mu \mathrm{IU} / \mathrm{mL}$ and $11.4 \pm 7.5 \mu \mathrm{IU} / \mathrm{mL}(P=$ $0.064)$, respectively. Homeostatic model assessment-insulin resistant (HOMA-IR) ([fasting insulin $(\mu \mathrm{IU} / \mathrm{mL}) \times$ fasting plasma glucose $(\mathrm{mmol} / \mathrm{L})] / 22.5)$ levels were $5.4 \pm 2.3$ and $5.4 \pm 5.8$ $(P=0.074)$, respectively, but these were not statistically significant (Table 4).

BWT reduction was evaluated according to initial BMI and $\mathrm{HbAlc}$. After 12 months of treatment, the degree of body weight

Table 4. Predictive parameters of body weight reduction for responders and nonresponders after dapagliflozin treatment

\begin{tabular}{lccc}
\hline Variable & Responder $(\mathrm{N}=23)^{\dagger}$ & ${\text { Non-responder }(\mathrm{N}=34)^{\dagger}}^{\dagger}$ & $P$ \\
\hline Age (yr) & $59.2 \pm 9.4$ & $57.8 \pm 10.0$ & 0.684 \\
DM duration $(\mathrm{yr})$ & $11.0 \pm 5.4$ & $12.3 \pm 5.6$ & 0.357 \\
BMI $\left(\mathrm{kg} / \mathrm{m}^{2}\right)$ & $27.4 \pm 18.3$ & $27.0 \pm 3.0$ & 0.922 \\
C-peptide $(\mathrm{ng} / \mathrm{mL})$ & $3.25 \pm 1.07$ & $2.62 \pm 1.02$ & $0.023^{*}$ \\
Insulin $(\mu \mathrm{lU} / \mathrm{mL})$ & $13.6 \pm 5.9$ & $11.4 \pm 7.5$ & 0.064 \\
HOMA-IR & $5.4 \pm 2.3$ & $5.4 \pm 5.8$ & 0.074 \\
HOMA- $\beta$ & $60.1 \pm 48.8$ & $49.4 \pm 40.0$ & 0.283 \\
\hline
\end{tabular}

Values are presented as mean \pm standard deviation.

${ }^{*} P<0.05$.

${ }^{t}$ Responder is defined patients who achieved $\geq 5 \%$ body weight reduction. Non-responder is classified those who achieved $<5 \%$ body weight reduction.

HOMA-IR, [FPI $(\mu \mathrm{lU} / \mathrm{ml}) \times \mathrm{FPG}(\mathrm{mmol} / \mathrm{L})] / 22.5$; HOMA- $\beta$, [20 $\times \mathrm{FPI}(\mu \mathrm{lU} / \mathrm{ml})] /[\mathrm{FPG}(\mathrm{mmol} /$ LL)-3.5.

Yr, year; DM, diabetes mellitus; BMI, body mass index; HOMA-IR, homeostatic model assessment-insulin resistant; HOMA- $\beta$, homeostatic model assessment-beta cell function; FPI, fasting plasma insulin; FPG, fasting plasma glucose.

Table 5. Changes in body weight value according to degree of $\mathrm{HbA} 1 \mathrm{c}$ reduction

\begin{tabular}{|c|c|c|}
\hline Change in $\mathrm{HbA} 1 \mathrm{c}(\%)$ & $\Delta \mathrm{BWT}(\mathrm{kg})$ & $P$ \\
\hline$\Delta \mathrm{HbA} 1 \mathrm{c} \leq-1.5(\mathrm{n}=10)$ & $-4.40 \pm 2.31$ & \\
\hline$-1.5<\Delta \mathrm{HbA} 1 \mathrm{c} \leq-1.0(\mathrm{n}=10)$ & $-2.25 \pm 1.59$ & \\
\hline$-1.0<\Delta \mathrm{HbA} 1 \mathrm{c} \leq-0.5(\mathrm{n}=11)$ & $-4.91 \pm 2.33$ & 0.070 \\
\hline$-0.5<\Delta \mathrm{HbA1c} \leq 0(\mathrm{n}=16)$ & $-3.06 \pm 2.14$ & \\
\hline $0<\Delta \operatorname{HbA1c}(\mathrm{n}=14)$ & $-2.82 \pm 3.65$ & \\
\hline
\end{tabular}

Values are presented as mean \pm standard deviation.

$\Delta$, difference in values before and after one year of treatment; BWT, body weight; HbA1c, glycated hemoglobin.

Table 6. Summary of treatment safety

\begin{tabular}{lc}
\hline Variable & Total $(\mathrm{n}=61)$ \\
\hline Discontinuation due to adverse reaction & 1 \\
Orthostatic dizziness & 3 \\
Genitourinary track infection & $2^{*}$ \\
Abdominal pain and diarrhea & 1 \\
Headache & 1
\end{tabular}

*bacterial prostatitis, bacterial vaginitis. reduction was not related to initial BMI or HbAlc level (Fig. 2). We also divided the participants based on mean changes from baseline HbAlc level into five categories: $\triangle \mathrm{HbAlc} \leq-1.5 ;-1.5<\Delta \mathrm{HbAlc}$ $\leq-1.0 ;-1.0<\Delta \mathrm{HbA} 1 \mathrm{c} \leq-0.5 ;-0.5<\Delta \mathrm{HbA} 1 \mathrm{c} \leq 0 ; 0<\Delta \mathrm{HbAlc}$ (Table 5). After 12 months of treatment, we found no significant difference in change from baseline body weight among these groups $(P=0.070)$.

\section{Tolerability and safety summary}

Frequent adverse events reported from dapagliflozin use included orthostatic dizziness (4.9\%) and genitourinary track infection (3.3\%). Only one patient had to discontinue dapagliflozin due to anxiety, tremors, and palpitations, which seemed to be associated with dehydration. Additional reported adverse events were abdominal pain (1.6\%), diarrhea (1.6\%), and headache (1.6\%). There were no serious adverse events, such as hypoglycemia. There were no significant changes in renal function according to dapagliflozin add-ons (Table 6).
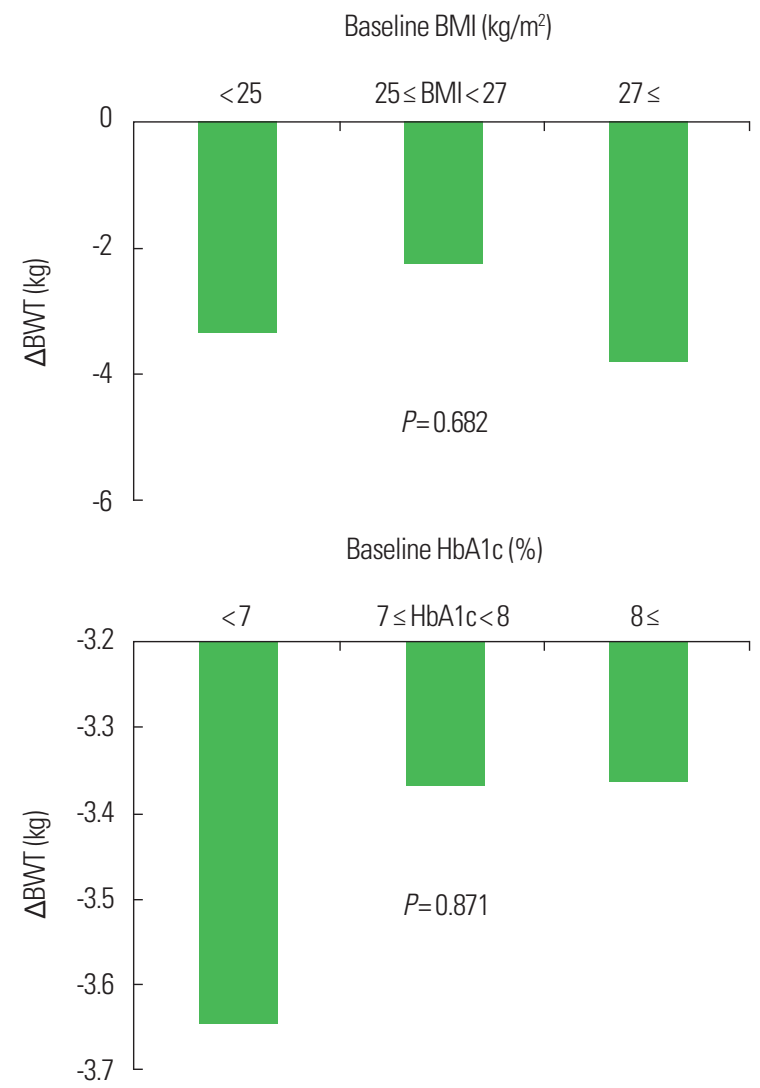

Figure 2. Change in body weight values according to baseline BMl and $\mathrm{HbA1c}$ levels. BMI, body mass index; HbA1c, glycated hemoglobin; BWT, body weight. 


\section{DISCUSSION}

A limited amount of data is available on Asian T2DM patients treated with dapagliflozin, especially regarding clinical practice and efficacy. In this study, we analyzed data from 61 type 2 diabetes patients who were administered dapagliflozin, and we evaluated the influencing factors for their response to therapy. Recently, obesity prevalence has rapidly increased because of consumption of a highfat diet and low physical activity. Obesity has been associated with diabetes incidence and complications. ${ }^{9}$ The mean BMI of Korean diabetic patients has gradually increased, up to $25.3 \pm 3.0 \mathrm{~kg} / \mathrm{m}^{2}$ in males and $25.2 \pm 3.4 \mathrm{~kg} / \mathrm{m}^{2}$ in females. ${ }^{10}$ Recent studies found that half of diabetic patients were obese. ${ }^{11,12}$ Additionally, oral antidiabetic drugs used to treat T2DM, such as sulfonylureas, insulins, and thiazolidinediones, can cause weight gain. ${ }^{13}$ Therefore, recent clinical efforts to develop treatment regimens that also focus on body weight reduction and glycemic control are valuable. Dapagliflozin causes a urinary loss of 60-80 g of glucose per day, which equates to a negative energy balance of 240-320 cal/day, or 0.9-1.3 $\mathrm{kg} / \mathrm{month}$, if this caloric deficit is not offset by an increase in caloric intake. Herein, we found that dapagliflozin had efficacy for body weight reduction in our diabetic subjects in each treatment group when the drug was administered in combination with other antidiabetic therapies. We found an average body weight reduction of $-3.4 \mathrm{~kg}$. Degree of reduction in body weight for the total group and according to a meta-analysis of dapagliflozin was $-3.4 \mathrm{~kg}$ and -2.1 $\mathrm{kg}$, respectively. ${ }^{14}$ According to two meta-analyses, the efficacy of empagliflozin and another SGLT2 inhibitor on body weight reduction were $-1.84 \mathrm{~kg}$ and $-1.80 \mathrm{~kg}$, respectively. ${ }^{15,16}$

Fasting C-peptide level was a significant predictor of body weight reduction in the dapagliflozin treatment groups $(3.25 \pm 1.07 \mathrm{ng} /$ $\mathrm{mL}$ in the responder group vs. $2.62 \pm 1.02 \mathrm{ng} / \mathrm{mL}$ in the non-responder group, $P=0.023)$. Also, both groups had high HOMA-IR level (5.4 \pm 2.3 among responders vs. $5.4 \pm 5.8$ among non-responders, $P=0.074)$. High fasting $\mathrm{C}$-peptide level indicates not only preserved insulin secretion, but also good beta cell function. ${ }^{10,17}$ Previous dapagliflozin studies showed improvement of insulin resistance with greater reduction of visceral fat rather than subcutaneous fat. ${ }^{13,16}$ We still do not understand the relationship between high fasting C-peptide level and degree of body weight re- duction in the dapagliflozin group. Therefore, we need to further evaluate mechanisms of good response factors among these patients, including glycemia and body weight reduction.

Although baseline HbA1c and PP2 levels were higher in the multiple drug combination groups (groups 2 and 3 ) than in the dual combination of metformin-dapagliflozin group (group 1), they were not inferior in any aspect of efficacy regarding $\mathrm{HbAlc}$ and $\mathrm{PP} 2$ reduction.

In summary, the initial combination of dapagliflozin with other ongoing therapy regimens might contribute synergistic effects on glycemic control for type 2 diabetes. Reduction rates in $\mathrm{HbAlc} \mathrm{lev-}$ el between the total subject sample in our study and according to a meta-analysis of dapagliflozin patients were $-0.61 \%$ and $-0.52 \%$, respectively. ${ }^{14}$ Additionally, two meta-analyses found that empagliflozin and another SGLT2 inhibitor decreased HbA1c level by $-0.62 \%$ and $-0.66 \%$, respectively. ${ }^{15,16}$

Our study has several limitations due to its retrospective design, including a small sample size and lack of more informative metabolic parameters for obesity, insulin resistance, and $\beta$-cell function. Therefore, further studies are needed that include abdominal circumference, dual-energy X-ray absorptiometry, and body composition. ${ }^{18}$

\section{CONFLICTS OF INTEREST}

The authors declare no conflict of interest.

\section{REFERENCES}

1. Holman RR, Paul SK, Bethel MA, Matthews DR, Neil HA. 10-year follow-up of intensive glucose control in type 2 diabetes. N Engl J Med 2008;359:1577-89.

2. ADVANCE Collaborative Group, Patel A, MacMahon S, Chalmers J, Neal B, Billot L, et al. Intensive blood glucose control and vascular outcomes in patients with type 2 diabetes. $\mathrm{N}$ Engl J Med 2008;358:2560-72.

3. Ferrannini E, Ramos SJ, Salsali A, Tang W, List JF. Dapagliflozin monotherapy in type 2 diabetic patients with inadequate glycemic control by diet and exercise: a randomized, double-blind, placebo-controlled, phase 3 trial. Diabetes Care 2010;33:2217-24. 
4. Bailey CJ, Gross JL, Pieters A, Bastien A, List JF. Effect of dapagliflozin in patients with type 2 diabetes who have inadequate glycaemic control with metformin: a randomised, double-blind, placebo-controlled trial. Lancet 2010;375:2223-33.

5. Nauck MA, Del Prato S, Meier JJ, Durán-García S, Rohwedder $\mathrm{K}$, Elze M, et al. Dapagliflozin versus glipizide as add-on therapy in patients with type 2 diabetes who have inadequate glycemic control with metformin: a randomized, 52-week, doubleblind, active-controlled noninferiority trial. Diabetes Care 2011;34:2015-22.

6. Strojek K, Yoon KH, Hruba V, Elze M, Langkilde AM, Parikh S. Effect of dapagliflozin in patients with type 2 diabetes who have inadequate glycaemic control with glimepiride: a randomized, 24-week, double-blind, placebo-controlled trial. Diabetes Obes Metab 2011;13:928-38.

7. Rosenstock J, Vico M, Wei L, Salsali A, List JF. Effects of dapagliflozin, an SGLT2 inhibitor, on HbAlc, body weight, and hypoglycemia risk in patients with type 2 diabetes inadequately controlled on pioglitazone monotherapy. Diabetes Care 2012; 35:1473-8.

8. Wilding JP, Woo V, Soler NG, Pahor A, Sugg J, Rohwedder K, et al. Long-term efficacy of dapagliflozin in patients with type 2 diabetes mellitus receiving high doses of insulin: a randomized trial. Ann Intern Med 2012;156:405-15.

9. Choi YJ, Kim HC, Kim HM, Park SW, Kim J, Kim DJ. Prevalence and management of diabetes in Korean adults: Korea National Health and Nutrition Examination Surveys 19982005. Diabetes Care 2009;32:2016-20.

10. Son JW, Park CY, Kim S, Lee HK, Lee YS; Insulin Resistance as Primary Pathogenesis in Newly Diagnosed, Drug Naïve Type 2 Diabetes Patients in Korea (SURPRISE) Study Group. Changing clinical characteristics according to insulin resistance and insulin secretion in newly diagnosed type 2 diabetic patients in Korea. Diabetes Metab J 2015;39:387-94.
11. Kim DJ, Song KE, Park JW, Cho HK, Lee KW, Huh KB. Clinical characteristics of Korean type 2 diabetic patients in 2005. Diabetes Res Clin Pract 2007;77 Suppl 1:S252-7.

12. Task Force Team for Basic Statistical Study of Korean Diabetes Mellitus of Korean Diabetes Association, Park IB, Kim J, Kim DJ, Chung CH, Oh JY, et al. Diabetes epidemics in Korea: reappraise nationwide survey of diabetes "diabetes in Korea 2007”. Diabetes Metab J 2013;37:233-9.

13. Iizuka $T$, Iemitsu $K$, Takihata $M$, Takai $M$, Nakajima $S$, Mina$\mathrm{mi}$ N, et al. Efficacy and safety of ipragliflozin in Japanese patients with type 2 diabetes: interim outcome of the ASSIGNK study. J Clin Med Res 2016;8:116-25.

14. Sun YN, Zhou Y, Chen X, Che WS, Leung SW. The efficacy of dapagliflozin combined with hypoglycaemic drugs in treating type 2 diabetes mellitus: meta-analysis of randomised controlled trials. BMJ Open 2014;4:e004619.

15. Liakos A, Karagiannis T, Athanasiadou E, Sarigianni M, Mainou M, Papatheodorou K, et al. Efficacy and safety of empagliflozin for type 2 diabetes: a systematic review and metaanalysis. Diabetes Obes Metab 2014;16:984-93.

16. Vasilakou D, Karagiannis T, Athanasiadou E, Mainou M, Liakos A, Bekiari E, et al. Sodium-glucose cotransporter 2 inhibitors for type 2 diabetes: a systematic review and meta-analysis. Ann Intern Med 2013;159:262-74.

17. Banu S, Jabir NR, Manjunath CN, Shakil S, Kamal MA. Cpeptide and its correlation to parameters of insulin resistance in the metabolic syndrome. CNS Neurol Disord Drug Targets 2011;10:921-7.

18. Bolinder J, Ljunggren Ö, Kullberg J, Johansson L, Wilding J, Langkilde AM, et al. Effects of dapagliflozin on body weight, total fat mass, and regional adipose tissue distribution in patients with type 2 diabetes mellitus with inadequate glycemic control on metformin. J Clin Endocrinol Metab 2012;97:1020-31. 